\title{
PENGUJIAN EFISIENSI PASAR \\ PADA PENGUMUMAN RIGHT ISSUE SAHAM CASA PT. CAPITAL FINANCIAL INDONESIA TBK
}

\author{
Sahroni ${ }^{1)}$ \\ 1) dosen universitas pamulang, email : sahroni.syarif@gmail.com
}

\section{ARTICLES \\ INFORMATION}

JURNAL SEKURITAS

(Saham, Ekonomi, Keuangan dan Investasi )

Vol.1, No.4, Juni 2018

Halaman : $16-23$

(c) LPPM \& Prodi Manajemen

UNIVERSITAS PAMULANG

ISSN (online) : 2581-2777

ISSN (print) : :2581-2696

\section{Keyword :}

Harga Saham CASA, Cum

Right Issue, Ex Right Issue,

Least Square Methods,

Dummy Variable.

JEL. classification :

C31, E50

\section{Contact Author :}

PRODI MANAJEMEN UNPAM

JL.Surya Kencana No.1 Pamulang

Tangerang Selatan - Banten

Telp. (021) 7412566, Fax (021) 7412491 Email:

jurnalfinance.unpam@gmail.com
Tujuan dari penelitian yaitu untuk membuktikan secara empirik pengumuman Cum Right Issue dan Ex Right Issue berpengaruh terhadap harga saham CASA. Analisis yang digunakan dalam penelitian ini adalah Least Squares Method dengan Dummy Variable. Data yang digunakan dalam penelitian diperoleh dari Bursa Efek Indonesia.. Penelitian menggunakan 80 sampel untuk diuji. Variable dependen penelitian adalah harga saham CASA, sedangkan variable independen menggunakan Dummy Variabel, yaitu D1 $=0$ adalah 40 sampel pengamatan sebelum pengumuman Right Issue yaitu tanggal 6 Desember 2017 sampai dengan tanggal Cum Right Issue tanggal 5 Januari 2018 dan Dummy Variable D2 $=1$ adalah pengamatan saat tanggal Ex Right Issue dan setelahnya, dari tanggal 8 Januari 2018 sampai 2 Februari 2018. Pengolahan data penelitian menggunakan software Eviews 9. Model yang diperoleh dari hasil penelitian adalah HARGA_SAHAM $=157.45+$ 115.1*DUMMY. Kesimpulan hasil dari penelitian yaitu Pengumuman Cum Right Issue dan Ex Right Issue berpengaruh sangat signifikan terhadap harga saham CASA.

The purpose of the research is to prove empirically the announcement of Cum Right Issue and Ex Right Issue affect the stock price of CASA. The analysis used in this research is Least Squares Method with Dummy Variable. The data used in the study were obtained from the Indonesia Stock Exchange. The study used 80 samples to be tested. The dependent variable of research is the stock price of CASA, while the independent variable using Dummy Variable, ie $D 1=0$ is 40 samples of observation before the announcement of Right Issue December 6, 2017 until the date of Cum Right Issue dated January 5, 2018 and Dummy Variable D2 $=1$ is the observation when the Ex Right Issue and thereafter, from January 8, 2018 to February 2, 2018. Data processing research using software Eviews 9. Model obtained from the research results are STOCK_PRICE $=157.45$ $+115.1{ }^{*}$ DUMMY. The conclusion of the result of research that is Announcement of Cum Right Issue and Ex Right Issue have a very significant effect to stock price of CASA. 


\section{A. Pendahuluan}

Salah satu cara yang ditempuh emiten untuk menambah modal yaltu dengan cara mengeluarkan saham baru. Dalam right issue, perseroan menawarkan hak (right) kepada pemegang saham yang ada untuk mendapatkan saham baru yang tentu saja berarti menyetor modal dengan rasio tertentu. Jika pemegang saham tersebut tidak mengambil haknya, maka ia dapat menjual haknya tersebut kepada investor lain. Dengan demikian di pasar modal juga dikenal perdagangan right. Jadi right adalah hak yang diberikan kepada pemegang saham lama untuk terlebih dahulu membeli saham yang baru dikeluarkan dengan tujuan agar para pemegang saham lama diberi kesempatan untuk mempertahankan persentase kepemilikannya dalam suatu perusahaan (Hendy, 2008).

Right issue merupakan sebuah aksi yang dilakukan perusahaan untuk menambah permodalannya dengan cara menerbitkan saham baru. Saham baru yang diterbitkan tersebut akan ditawarkan dulu kepada pemilik saham lama. Dana yang didapatkan dan right issue ini biasanya digunakan pihak managemen untuk melakukan ekspansi usaha. Dalam melakukan right issue kita akan mendengar kata HMETD. Kata tersebut merupakan singkatan dan Hak Memesan Efek Terlebih Dahulu, yaltu hak yang diberikan kepada para pemilik saham lama. Sarna halnya dengan dividen, right issue juga memiliki tanggal cum yang berupa tanggal terakhir pencatatan untuk menentukan hak dan masing-masing pemilik saham lama. Sifat dan right issue ini "bebas' artinya investor lama boleh membeli saham baru dan boleh juga tidak mernbelinya. Narnun, jika pemilik saham lama tidak membeli saham baru, porsi kepemilikian sahamnya akan dikatakan terdilusi atau berkurang (Joko, 2010).

Salah satu perusahaan go public yang menjadi perhatian peneliti adalah PT. Capital Financial Indonesia Tbk, dimana perusahaan ini tercatat di Bursa Efek Indonesia dengan kode saham CASA. Kegiatan utama perusahaan bergerak di bidang investasi dan jasa keuangan. Peneliti tertarik untuk mempelajari pergerakan harga saham CASA khususnya pada saat sebelum dan sesudah pengumuman Right Issue oleh Kustodian Sentral Efek Indonesia. Hasil penelitian diharapkan dapat memberikan kontribusi di bidang ilmu pengetahuan bagi dunia akademik, yaitu pengembangan teori efsiensi pasar (Fama, 1970) dan menjadi masukan bagi investor dan masyarakat, khusunya dalam pengambilan keputusan investasi

\section{B. Perumusan Masalah}

Perumusan masalah dalam penelitian yaitu apakah pengumuman Cum Right Issue dan Ex Right Issue dapat mempengaruhi harga saham CASA ?

\section{Tujuan Penelitian}

Penelitian bertujuan untuk membuktikan secara empirik pengumuman Cum Right Issue dan Ex Right Issue berpengaruh terhadap harga saham CASA 


\section{Landasan Teori}

\section{$\underline{\text { Right Issue }}$}

Pasca penawaran umum perdana (IPO), emiten dapat melakukan penambahan modal yaitu dengan melakukan Penawaran Umum Terbatas atau yang lebih dikenal dengan sebutan Right Issue.Right Issue adalah suatu cara bagi emiten untuk meningkatkan jumlah modal disetornya dengan memberikan penawaran terlebih dahulu kepada pemegang saham lama untuk menambah modalnya di perusahaan tersebut. Jika seorang investor tidak ingin menggunakan hak tersebut, maka dia dapat menjual hak tersebut, atau dengan kata lain hak tersebut dapat diperjualbelikan, sehingga muncul periode perdagangan right. Right issue terkait erat dengan Pre-emptive Right (hak yang dimiliki oleh pemegang saham untuk mempertahankan persentase kepemilikannya). Sebagaimana diatur dalam Peraturan Bapepam No. IX.D.1 tentang Hak Memesan Efek Terlebih Dahulu khususnya butir 2 perdagangan right (Hendy, 2008).

Right issue terkait erat dengan Pre-emptive Right (hak yang dimilikioleh pemegang saham untuk mempertahankan persentase kepemilikannya). Sebagaimana diatur dalam Peraturan Bapepam No. IX.D.1 tentang Hak Memesan Efek Terlebih Dahulu khususnya butir 2 disebutkan bahwa "Apabila suatu perusahaan yang telah melakukan Penawaran Umum saham atau Perusahaan Publik bermaksud untuk menambah modal sahamnya, termasuk melalul penerbitan Waran atau Efek Konversi, maka setiap pemegang saham harus diberi Hak Memesan Efek Terlebih Dahulu sebanding dengan persentase pemilikan mereka (Hendy, 2008)

Ada beberapa alasan emiten melakukan Right Issue. Secara umum,right issue ditujukan untuk memperkuat permodalan suatu perusahaan. Dana dan hasil right issue dapat digunakan untuk berbagai tujuan misalnya melakukan ekspansi usaha, melunasi pembayaran utang, atau akuisisi internal. Beberapa emiten perbankan melakukan right issue untuk memperkuat struktur modal dan meningkatkan Rasio Kecukupan Modal (CAR). Pada pninsipnya, right issue merupakan bagian tidak terpisahkan dari strategi perusahaan dalam rangka memperkuat daya saing (competitive position). Namun demikian, tidak selalu strategi tersebut diterima dengan baik oleh investor sehingga terkadang dalam right issue terjadi pro dan kontra di kalangan investor. Bagi investor yang tidak tertarik dengan right issue maka investor tersebut tidak akan mengambil bagian dan konsekuensinya akan mengalami dilusi/penurunan persentase kepemilikan(Hendy, 2008).

\section{Teori Efisiensi Pasar}

Pasar modal dikatakan efisien (efficient capital market) jika harga-harga sekuritas "mencerminkan secara penuh" informasi yang tersedia (a security market is efficient if security prices "fully reflect" the information available). Harga-harga 
dengan cepat menyesuaikan sesaat setelah ada informasi baru, dan setelah penyesuaian para investor tidak akan mampu mendapatkan keuntungan abnormal (abnormal return) dengan memanipulasi informasi yang tersedia khusus baginya. Semakin cepat informasi baru tercermin pada harga sekuritas, maka semakin efisien pasar modal tersebut (Fama, 1970). Fama (1970) membaginya ke dalam hipotesis pasar efisien berbentuk lemah, hipotesis pasar efisien berbentuk setengah kuat dan hipotesis pasar efisien berbentuk kuat. Yang dimaksud dengan informasi yang relevan dapat diklasifikasikan menjadi tiga tipe: Informasi dalam bentuk perubahan harga di waktu yang lalu, Informasi yang tersedia kepada publik (public information) dan Informasi yang tersedia baik kepada publik maupun tidak (public dan private information). Pada tahun 1991, Fama mengemukakan penyempurnaan atas klasifikasi efisiensi pasar tersebut. Efisiensi bentuk lemah disempurnakan menjadi suatu klasifikasi yang lebih bersifat umum untuk menguji prediktabilitas return (return predictability). Pada klasifikasi ini, informasi mengenai pola return sekuritas, seperti return yang tinggi di bulan Januari dan hari Senin, tidak dapat digunakan untuk memperoleh abnormal return. Sedangkan efisiensi bentuk setengah kuat dan efisiensi bentuk kuat diubah menjadi event studies, dan pengujian efisiensi pasar dalam bentuk kuat disebut sebagai pengujian private information.

\section{E. Metodologi}

Perusahaan yang menjadi objek penelitian yaitu PT. Capital Financial Indonesia Tbk, yang beralamat di Sona Topas Tower, Lt. 9 Jl. Jend Sudirman Kav 26, Jakarta. Pengamatan dilakukan pada tanggal 6 Desember 2017 sampai dengan 2 Februari 2018. Penelitian ini termasuk ke dalam ruang lingkup penelitian manajemen keuangan, yang secara khusus melakukan pengujian efisiensi pasar pada pengumuman right issue saham CASA (PT. Capital Financial Indonesia Tbk). Teknik pengambilan sampel dalam penelitian ini menggunakan nonprobability purposive sampling, dimana sampel yang diambil dari populasi ditentukan berdasarkan pertimbangan tertentu (Sugiyono, 2013). Penelitian ini menggunakan data harian menggunakan 80 sampel harga saham sebelum dan sesudah Pengumuman Right Issue dengan menggunakan variable Dummy (Bambang, 2009). Pengumpulan data yang digunakan dalam penelitian ini adalah data primer dan sekunder yang diperoleh dari Bursa Efek Indonesia (www.idx.co.id), www.duniainvestasi.com dan dari website resmi PT Capital Financial Indonesia Tbk (www.capitalfinancial.co.id). Metode analisis yang digunakan dalam penelitian ini adalah Least Squares Method dengan Dummy Variable dan pengolahan data menggunakan Eviews 9 (Bambang dan Junaidi, 2012), (Gujarati, 2010). 


\section{F. Hasil dan Pembahasan}

Hasil penelitian berdasarkan data yang diperoleh diuraikan pada tabel berikut:

Tabel. Data Variabel Penelitian

\begin{tabular}{|r|r|r|r|}
\hline No. & Tanggal & Dummy & Harga Saham \\
\hline 1 & $6 / 12 / 2017$ & 0 & 159 \\
\hline 2 & $7 / 12 / 2017$ & 0 & 158 \\
\hline 3 & $8 / 12 / 2017$ & 0 & 158 \\
\hline 4 & $11 / 12 / 2017$ & 0 & 158 \\
\hline 5 & $12 / 12 / 2017$ & 0 & 158 \\
\hline 6 & $13 / 12 / 2017$ & 0 & 158 \\
\hline 7 & $14 / 12 / 2017$ & 0 & 158 \\
\hline 8 & $15 / 12 / 2017$ & 0 & 158 \\
\hline 9 & $18 / 12 / 2017$ & 0 & 156 \\
\hline 10 & $19 / 12 / 2017$ & 0 & 155 \\
\hline 11 & $20 / 12 / 2017$ & 0 & 154 \\
\hline 12 & $21 / 12 / 2017$ & 0 & 154 \\
\hline 13 & $22 / 12 / 2017$ & 0 & 154 \\
\hline 14 & $27 / 12 / 2017$ & 0 & 155 \\
\hline 15 & $28 / 12 / 2017$ & 0 & 154 \\
\hline 16 & $29 / 12 / 2017$ & 0 & 154 \\
\hline 17 & $2 / 1 / 2018$ & 0 & 155 \\
\hline 18 & $3 / 1 / 2018$ & 0 & 177 \\
\hline 19 & $4 / 1 / 2018$ & 0 & 156 \\
\hline 20 & $5 / 1 / 2018$ & 0 & 160 \\
\hline
\end{tabular}

\begin{tabular}{|r|r|r|r|}
\hline No. & \multicolumn{1}{|c|}{ Tanggal } & Dummy & Harga Saham \\
\hline 21 & $8 / 1 / 2018$ & 1 & 216 \\
\hline 22 & $9 / 1 / 2018$ & 1 & 270 \\
\hline 23 & $10 / 1 / 2018$ & 1 & 252 \\
\hline 24 & $11 / 1 / 2018$ & 1 & 210 \\
\hline 25 & $12 / 1 / 2018$ & 1 & 168 \\
\hline 26 & $15 / 1 / 2018$ & 1 & 195 \\
\hline 27 & $16 / 1 / 2018$ & 1 & 236 \\
\hline 28 & $17 / 1 / 2018$ & 1 & 280 \\
\hline 29 & $18 / 1 / 2018$ & 1 & 270 \\
\hline 30 & $19 / 1 / 2018$ & 1 & 268 \\
\hline 31 & $22 / 1 / 2018$ & 1 & 264 \\
\hline 32 & $23 / 1 / 2018$ & 1 & 276 \\
\hline 33 & $24 / 1 / 2018$ & 1 & 278 \\
\hline 34 & $25 / 1 / 2018$ & 1 & 274 \\
\hline 35 & $26 / 1 / 2018$ & 1 & 322 \\
\hline 36 & $29 / 1 / 2018$ & 1 & 320 \\
\hline 37 & $30 / 1 / 2018$ & 1 & 316 \\
\hline 38 & $31 / 1 / 2018$ & 1 & 350 \\
\hline 39 & $1 / 2 / 2018$ & 1 & 342 \\
\hline 40 & $2 / 2 / 2018$ & 1 & 344 \\
\hline
\end{tabular}

Yang menjadi variable dependen penelitian adalah harga saham dengan 40 sampel sebelum Pengumuman Right Issue dan 40 sampel setelah Pengumuman Right Issue. Variable independen dalam penelitian ini adalah variable dummy, yaitu

D1 = 0 adalah 40 sampel pengamatan sebelum pengumuman Right Issue yaitu tanggal 6 Desember 2017 sampai dengan tanggal cum Right Issue tanggal 5 Januari 2018.

$\mathrm{D} 2=1$ adalah pengamatan saat tanggal ex Right Issue dan setelahnya, dari tanggal 8 Januari 2018 sampai 2 Februari 2018

Hasil pengolahan/analisis data penelitian menggunakan Eviews 9 Least Squares Method dengan Dummy Variable adalah sebagai berikut: 
Dependent Variable: HARGA_SAHAM

Method: Least Squares

Date: 03/14/18 Time: 08:27

Sample: 140

Included observations: 40

\begin{tabular}{lrlll}
\hline \hline \multicolumn{1}{c}{ Variable } & Coefficient & Std. Error & t-Statistic & Prob. \\
\hline \hline \multicolumn{1}{c}{ C } & 157.4500 & 8.031967 & 19.60292 & 0.0000 \\
\multicolumn{1}{c}{ DUMMY } & 115.1000 & 11.35892 & 10.13301 & 0.0000 \\
\hline \hline R-squared & 0.729879 & Mean dependent var & 215.0000 \\
Adjusted R-squared & 0.722771 & S.D. dependent var & 68.22091 \\
S.E. of regression & 35.92005 & Akaike info criterion & 10.04917 \\
Sum squared resid & 49029.50 & Schwarz criterion & 10.13362 \\
Log likelihood & -198.9835 & Hannan-Quinn criter. & 10.07971 \\
F-statistic & 102.6779 & Durbin-Watson stat & 0.396783 \\
Prob(F-statistic) & 0.000000 & & & \\
\hline \hline
\end{tabular}

Estimation Command:

LS HARGA_SAHAM C DUMMY

Estimation Equation:

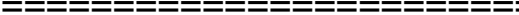

HARGA_SAHAM $=\mathrm{C}(1)+\mathrm{C}(2)^{*}$ DUMMY

Substituted Coefficients:

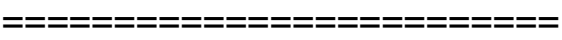

HARGA_SAHAM $=157.45+115.1{ }^{*}$ DUMMY

Pembahasan

Pergerakan harga saham CASA secara umum mengalami peningkatan dari bulan desember 2017 sampai bulan Januari 2018. Jika dikaitkan dengan Pengumuman Right Issue terlihat adanya hubungan. Hal ini dapat dilihat dari nilai $R$ Square sebesar 0.729879 yang berarti bahwa Pengumuman Right Issue memberikan kontribusi sebesar $72,9879 \%$ terhadap Harga Saham CASA, sedangkan sisanya sebesar $27.0121 \%$ dikontribusikan oleh variable lain diluar penelitian. Model hasil penelitian yang diperoleh adalah HARGA_SAHAM $=157.45+115.1{ }^{*}$ DUMMY

Variable independen penelitian menggunakan Dummy Variabel, yaitu D1 $=0$ adalah 40 sampel pengamatan sebelum pengumuman Right Issue yaitu tanggal 6 Desember 2017 sampai dengan tanggal cum Right Issue tanggal 5 Januari 2018 dan Dummy Variable D2 $=1$ adalah pengamatan saat tanggal ex Right Issue dan setelahnya, dari tanggal 8 Januari 2018 sampai 2 Februari 2018. Menunjukkan nilai coefficient 115.1000 yang lebih besar dari Standard Error 11.35892. Hal ini menunjukkan bahwa Dummy Variabel (Pengumuman Right Issue) mempunya pengaruh terhadap Harga Saham CASA. Berikut ini peneliti menampilkan pergerakan Harga Saham CASA sebelum dan sesudah Pengumuman Right Issue: 


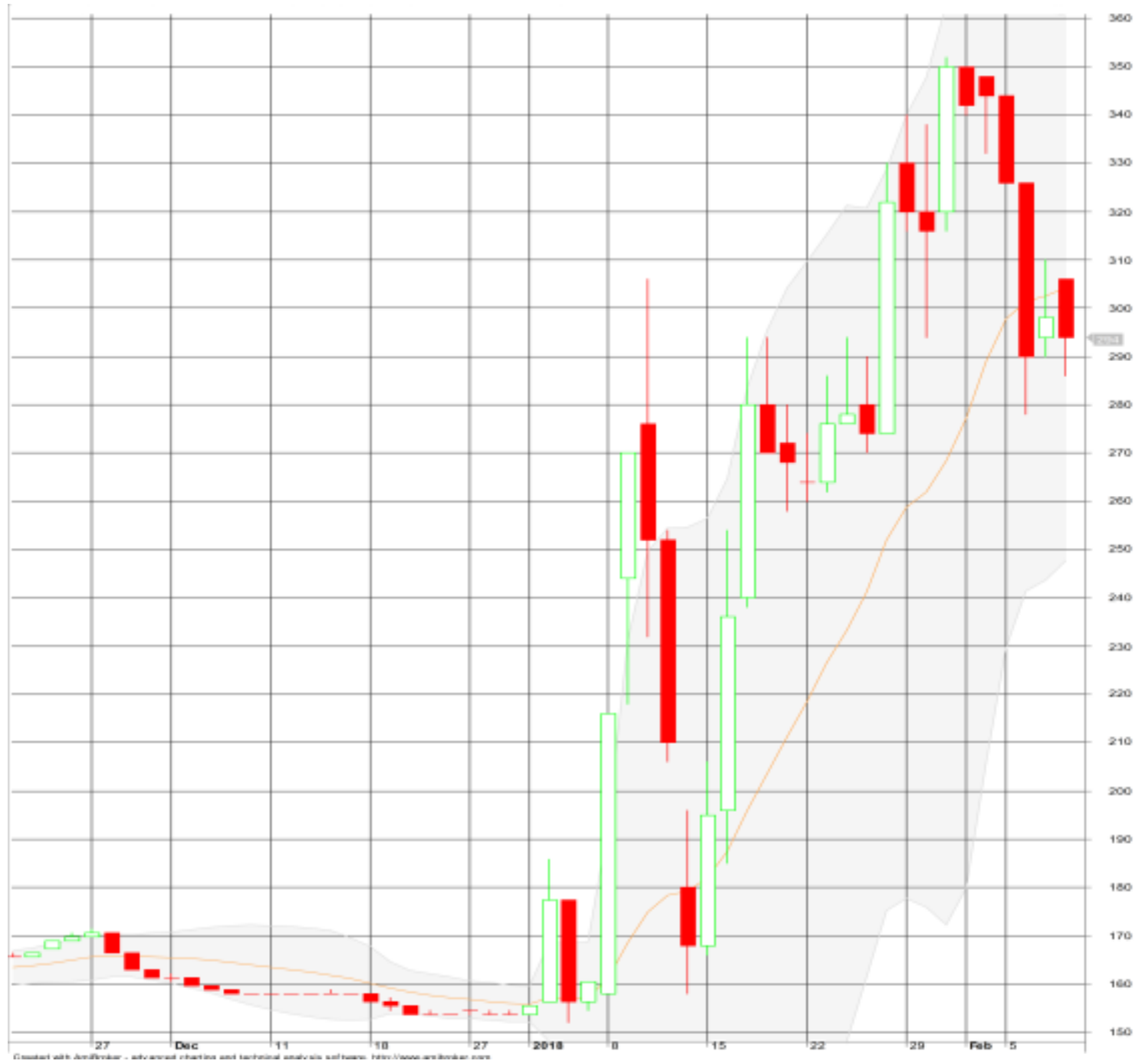

Gambar 1. Pergerakan Harga Saham CASA 6 Desember 2017- 2 Februari 2018

Kemudian Hasil pengolahan dengan Eviews menunjukkan $p$ value significant level sebesar 0.0000 dimana nilai $p$ value ini berada dibawah $5 \%$ dan dibawah $1 \%$ yang berarti bahwa pengumuman Right Issue berpengaruh sangat signifikan terhadap harga saham CASA. Diharapkan hasil penelitian ini dapat dijadikan kontribusi bagi dunia ilmu pengetahuan khususnya Efisiensi Pasar dalam IImu Manajemen Keuangan di bidang Pasar Modal. Hasil penelitian juga diharapkan dapat dijadikan bahan pertimbangan dalam keputusan investasi bagi investor dan masyarakat. Saran peneliti untuk penelitian selanjutnya, ada variable lain diluar penelitian yang dapat mempengaruhi harga saham CASA pada pengumuman Right Issue. Peneliti mengharapkan adanya penelitan lanjutan untuk pengembangan ilmu pengetahuan.

\section{G. Kesimpulan}

Hasil penelitian menunjukkan bahwa Pengumuman Cum Right Issue dan Ex Right Issue berpengaruh sangat signifikan terhadap harga saham CASA. 


\section{H. Daftar Pustaka}

Bambang Juanda, Junaidi. 2012. Ekonometrika Deret Waktu Teori dan Aplikasi, Penerbit PT. Penerbit IPB Press, Kampus IPB Taman Kencana Bogor.

Bambang Juanda. 2009. Ekonometrika: Pemodelan dan Pendugaan, IPB Press, Bogor.

Fama, Eugene F. 1970. Efficient Capital Markets: A Review of Theory and Empirical Work. The Journal of Finance, Vol. 25, No. 2, Papers and Proceedings of the Twenty-Eighth Annual Meeting of the American Finance Association New York, N.Y. December, 28-30, 1969 (May, 1970), pp. 383-417

Fama, Eugene F. 1991. Efficient Capital Markets: II. The Journal of Finance, Vol. 46, No. 5 (Dec., 1991), pp. 1575-1617. Published by: Blackwell Publishing for the American Finance Association

Gujarati, N. Damodar, dan Porter, C. Dawn. 2010. Basic Econometrics, $5^{\text {th }}$ edition, The McGraw-Hill Companies.

Hendy M Fakhruddin. 2008. Go Public: Strategi Pendanaan dan Peningkatan Nilai Perusahaan. PT Elex Media Komputindo - Gramedia, Jakarta.

Hendy M Fakhruddin. 2008. Istilah Pasar Modal A-Z. PT Elex Media Komputindo Gramedia, Jakarta.

Joko Salim. 2010. 108 Tanya Jawab Tentang Investasi. Transmedia Pustaka, Jakarta.

Nardi Sunardi (2017) Determinan Kebijakan Utang Serta Implikasinya terhadap Kinerja

Perusahaan (Perusahaan yang tergabung dalam indeks LQ.45 yang terdaftar di Bursa Efek Indonesia Tahun 2011- 2015) Jurnal Sekuritas, Vol. 1, No.1 / September 2017 Universitas Pamulang.

Nardi Sunardi, Aceng Abdul Hamid, Lativa, Abdul Kadim, Natanael Tulus (2018) Determinant Of Cost Efficiency And It's Implications For Companies Performance Incorporated In The Lq.45 Index Listing In Idx For The Period of 2011-2016, International Journal of Applied Business and Economic Research,.Volume 16, Number 1, 2018, ISSN : 0972-7302

Sugiyono. 2013. Metode Penelitian Kuantitatif, Kualitatif dan Kombinasi (Mixed Methods). Cetakan ke-4, Penerbit Alfabeta, Bandung.

www.capitalfinancial.co.id

www.duniainvestasi.com

www.idx.co.id

www.ksei.co.id 